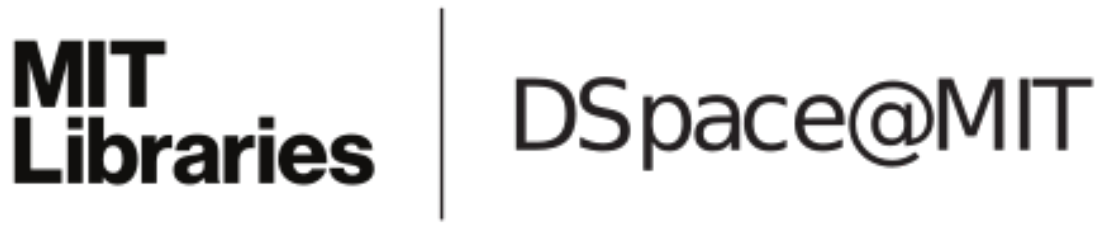

\author{
MIT Open Access Articles
}

Stable Open-Shell Phosphorane Based on a Redox-Active Amidodiphenoxide Scaffold

The MIT Faculty has made this article openly available. Please share how this access benefits you. Your story matters.

Citation: Pistner, Allen J. et al. “Stable Open-Shell Phosphorane Based on a Redox-Active Amidodiphenoxide Scaffold." Inorganic Chemistry 56, 15 (June 2017): 8661-8668 (c) 2017 American Chemical Society

As Published: http://dx.doi.org/10.1021/acs.inorgchem.7b00657

Publisher: American Chemical Society (ACS)

Persistent URL: http://hdl.handle.net/1721.1/117203

Version: Author's final manuscript: final author's manuscript post peer review, without publisher's formatting or copy editing

Terms of Use: Article is made available in accordance with the publisher's policy and may be subject to US copyright law. Please refer to the publisher's site for terms of use. 


\title{
A Stable Open-Shell Phosphorane based on a Redox Active Amidodiphenoxide Scaffold
}

\author{
Allen J. Pistner, ${ }^{\star}$ Hye Won Moon ${ }^{\dagger}$ Alexey Silakov, ${ }^{\star}$ Hemant P. Yennawar ${ }^{\ddagger}{ }^{\S}$ and Alexander T. Radose- \\ vich $*, \dagger$ \\ ${ }^{\dagger}$ Department of Chemistry, Massachusetts Institute of Technology, Cambridge, Massachusetts 02139 \\ * Department of Chemistry, The Pennsylvania State University, University Park, Pennsylvania 16802 \\ ${ }^{\S}$ X-ray Crystallography Laboratory, Department of Biochemistry and Molecular Biology, The Pennsylvania State Universi- \\ ty, University Park, Pennsylvania 16802
}

\section{Supporting Information Placeholder}

\begin{abstract}
The synthesis and redox reactivity of pentacoordinate phosphorus compounds incorporating a redox active $O N O$ amidodiphenoxide scaffold ( $O N O=N, N$-bis(3,5-di-tert-butyl-2-phenoxide)amide) are described. Dichloro- and diphenylphosphoranes, $\mathbf{2} \cdot \mathrm{Cl}_{2}$ and $\mathbf{2} \cdot \mathrm{Ph}_{2}$ respectively, are synthesized and crystallographically characterized. Cyclic voltammograms of $\mathbf{2} \cdot \mathrm{Cl}_{2}$ show only a single irreversible oxidation $\left(\mathrm{E}_{p a}=+0.83 \mathrm{~V}\right.$ vs $\mathrm{Cp}_{2} \mathrm{Fe}^{\mathrm{o} /+}$ ), while the diphenyl analogue $2 \cdot \mathrm{Ph}_{2}$ is reversibly oxidized at lower applied potential $\left(\mathrm{E}_{1 / 2}=+0.47 \mathrm{~V}\right.$ vs $\left.\mathrm{Cp}_{2} \mathrm{Fe}^{\mathrm{o} /+}\right)$. Chemical oxidation of $2 \cdot \mathrm{Ph}_{2}$ with $\mathrm{AgBF}_{4}$ produces the corresponding radical cation $\left[2 \cdot \mathrm{Ph}_{2}\right]^{++}$, where EPR spectroscopy and DFT calculations reveal that the unpaired spin density is largely ligand based and is highly delocalized throughout the $O N O$ framework of the paramagnetic species. The solid state structures indicate only minor geometrical changes between the neutral $\mathbf{2} \cdot \mathrm{Ph}_{2}$ and oxidized $\left[\mathbf{2} \cdot \mathrm{Ph}_{2}\right]^{++}$species, consistent with fast self-exchange electron transfer as observed by NMR line-broadening experiments.
\end{abstract}

\section{INTRODUCTION}

Interest in molecular inorganic compounds with redox active ligand scaffolds has been increasing because the distribution of redox properties across both metal and ligand alters the density and nature of frontier electronic states. ${ }^{1}$ Such cooperative redox reactivity presents opportunities for new multielectron transformations..$^{2-5}$ Catalysts employing redox active ligands continue to make significant advances in synthetic chemistry and have been the subject of several recent reviews. ${ }^{6-10}$

Among the most actively investigated redox-active scaffolds has been the ONO chelate N,N-bis(3,5-di-tert-butyl-2phenoxide)amide A. Prepared initially as a binding fragment for heavy main group metals by Stegmann and Scheffler, ${ }^{11-13}$ compound $\mathbf{A}$ exhibits a rich chelating chemistry for diverse transition metal and main group elements. ${ }^{14-29}$ Chief among the findings in such studies is the propensity of the $O N O$ fragment to support several discrete redox states as depicted in Figure 1: closed-shell trianionic $\mathbf{A}$, open-shell dianionic semiquinonate $\mathbf{B}$, and monoanionic quinonate $\mathbf{C}$. Access to each of these electronic states may be controlled not only on the identity of the chelated element, but also by external reagents in such a way as to permit catalysis involving reversible interconversion of several or all of these electronic configurations. ${ }^{30}$

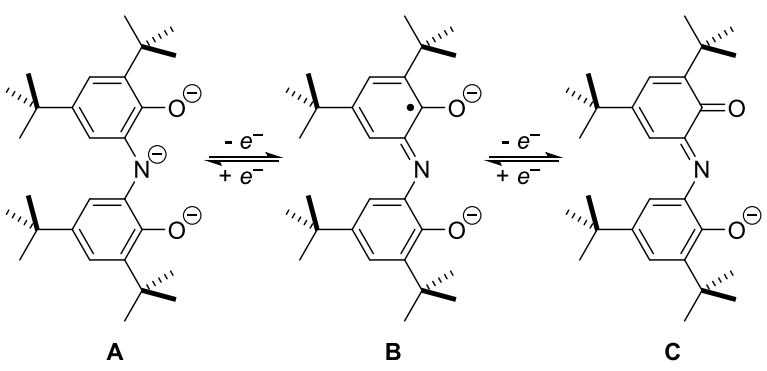

Figure 1. Redox states of the amidodiphenoxide $O N O$ scaffold A-C.

We have been investigating the chemistry of phosphorus compounds supported within heteroatom-based trianionic binding motifs. For instance, we have reported on both $\mathrm{ONO}$ and $N N N$-supported phosphorus compounds that undergo intermolecular oxidative addition of $\mathrm{E}-\mathrm{H}$ bonds $(\mathrm{E}=\mathrm{O}, \mathrm{N})$, in some cases reversibly. ${ }^{31,32}$ Aldridge and Goicoechea have subsequently reported in a similar vein with phosphorus compounds based on supporting structure A.$^{33,34}$ Many structurally related neutral phosphoranes in this series are known, especially from the studies of Contreras and workers. ${ }^{35}$ Despite the well-known redox reactivity of $\mathbf{A}-\mathbf{C}$, the preparation of phosphorus compounds incorporating the $O N O$ fragment in its open shell electronic configuration $\mathbf{B}$ has not been demonstrated explicitly to date. 
In the interest of better understanding the interplay between phosphorus(V) and $O N O$ ligand electronic states, we describe here the synthesis, structural and electronic properties of several closed- and open-shell phosphorus compounds based on the $N, N$-bis(3,5-di-tert-butyl-2-phenoxide)amide chelate. We demonstrate the redox activity of $O N O$-supported phosphoranes through electrochemical and chemical oxidation and characterize the extent of electron-hole delocalization through EPR spectroscopic and DFT theoretical methods Our results are consistent with the presence of accessible and reversible ligand centered oxidation events in these compounds, suggesting a possible role in future reactivity studies.

\section{RESULTS AND DISCUSSION}

Synthesis and Structure of Closed-Shell Phosphoranes. Investigation was initiated with the preparation of two related closed-shell phosphoranes with varying substituents at phosphorus (Figure 2). The synthesis began with the preparation of homoleptic zinc complex $\mathbf{1}$ from the multicomponent selfassembly reaction of $\mathrm{Zn}(\mathrm{OAc})_{2}$, 3,5-di-tert-butylcatechol and ammonia following the procedure of Girgis and Balch. ${ }^{36}$ From 1, phosphoranes $\mathbf{2} \cdot \mathrm{Cl}_{2}$ and $\mathbf{2} \cdot \mathrm{Ph}_{2}$ can be accessed directly by treatment with trichlorophosphine $\left(\mathrm{PCl}_{3}\right)$ and chlorodiphenylphosphine $\left(\mathrm{PClPh}_{2}\right)$, respectively, in a modification of the synthetic procedure previously reported by Contreras and coworkers. ${ }^{32}$ The ${ }^{31} \mathrm{P}$ NMR chemical shift for each species falls in the range expected for pentacoordinated phosphorus $\left(\delta_{2} \cdot \mathrm{Cl}_{2}=-20.1 \mathrm{ppm} ; \delta_{2} \cdot \mathrm{Ph}_{2}=-27.9 \mathrm{ppm}\right)$. In effect, the addition of the tricoordinate phosphorus reagents to $\mathbf{1}$ results in formal reduction of the ONO ligand from its iminoquinone oxidation state ( $c f . \mathbf{C}$ ) to the trianionic amidodiphenoxide state ( $f$. A) with formal oxidation of the phosphorus center to the $\mathrm{P}(\mathrm{V})$ oxidation state. Both $\mathbf{2} \cdot \mathrm{Cl}_{2}$ and $\mathbf{2} \cdot \mathrm{Ph}_{2}$ are prepared in high yield according to this route (73\% and $79 \%$, respectively).

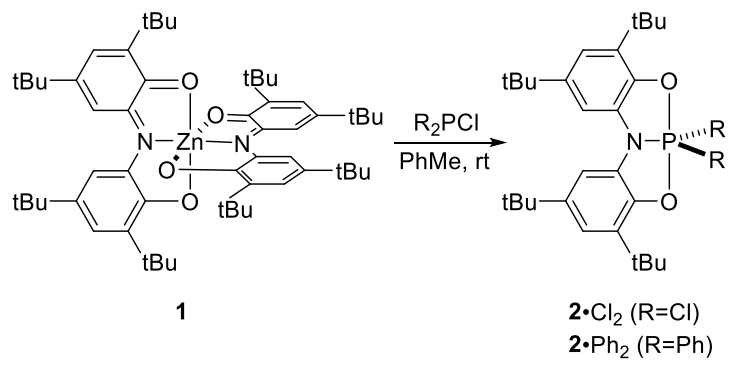

Figure 2. Synthesis of $\mathbf{2} \cdot \mathrm{Cl}_{2}$ and $\mathbf{2} \cdot \mathrm{Ph}_{2}$.

Single crystals of $\mathbf{2} \cdot \mathrm{Ph}_{2}$ were obtained by slow evaporation of an acetonitrile/methylene chloride solution, and the structure of $\mathbf{2} \cdot \mathrm{Ph}_{2}$ was elucidated by X-ray diffraction analysis. As depicted in the thermal ellipsoid plot in Figure 3, compound $\mathbf{2} \cdot \mathrm{Ph}_{2}$ exhibits a trigonal bipyramidal geometry $(\tau=0.85)$, with the phenyl fragments occupying two basal sites and the $O N O$ fragment spanning the remaining one basal and two apical positions. Selected bond lengths and angles are collected in Table 1. The phosphorus and three basal substituents are effectively coplanar, with the sum of the angles about phosphorus $\Sigma \angle \mathrm{X}-\mathrm{P}_{1}-\mathrm{Y}=360.02^{\circ}$. Within this plane, the bond angles $\angle \mathrm{N}_{1}-\mathrm{P}_{1}-\mathrm{C}_{1}$ and $\angle \mathrm{N}_{1}-\mathrm{P}_{1}-\mathrm{C}_{7}$ were measured to be $122.37(8)^{\circ}$ and $123.59(9)^{\circ}$, respectively, while the $\angle \mathrm{C}_{1}-\mathrm{P}_{1}-\mathrm{C}_{7}$ is slightly compressed at $114.04(10)^{\circ}$. The oxygen substituents are only modestly deformed away from rigorously diapical positions by the tridentate chelating motif (bond angle $\angle \mathrm{O}_{1}-\mathrm{P}_{1}-\mathrm{O}_{2}=$ $\left.174.72(6)^{\circ}\right)$. Bond lengths $d\left(\mathrm{O}_{1}-\mathrm{P}_{1}\right)$ and $d\left(\mathrm{O}_{2}-\mathrm{P}_{1}\right)$ exhibit a slight dissymmetry (1.6985(18) $\AA$ and 1.7048(18) $\AA$, respectively) but otherwise fall within the expected range of oxygenphosphorus distances in pentacoordinated phosphorus. The $\mathrm{N}_{1}-\mathrm{P}_{1}$ bond was found to be of similar length $(1.699(2) \AA)$ as the O-P bonds, whereas the carbon-phosphorus bonds to the phenyl are somewhat longer at 1.807(2) $\AA$ and 1.800(2) $\AA$ for $d\left(\mathrm{C}_{1}-\mathrm{P}_{1}\right)$ and $d\left(\mathrm{C}_{7}-\mathrm{P}_{1}\right)$, respectively.

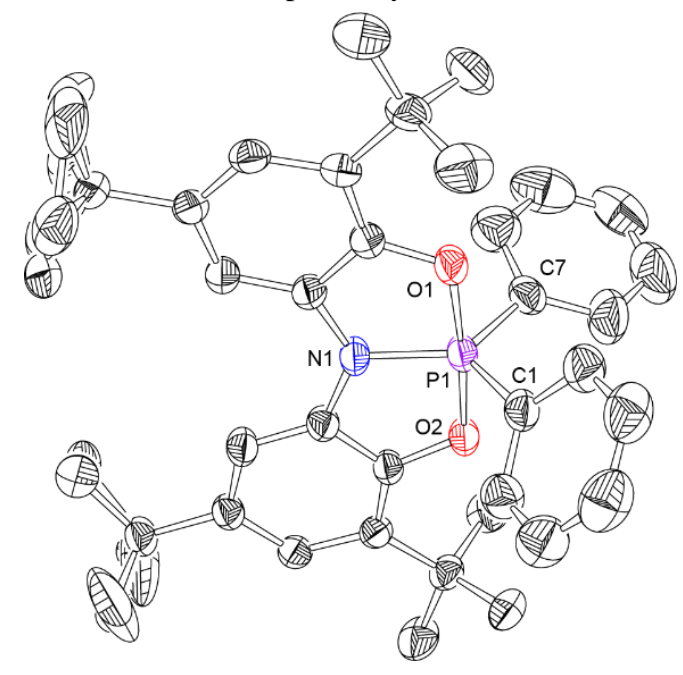

Figure 3. Solid state structure of $\mathbf{2} \cdot \mathrm{Ph}_{2}$. Thermal ellipsoids shown at $50 \%$ probability with the hydrogens atoms omitted for clarity.

Electrochemistry of Phosphoranes $\mathbf{2} \cdot \mathrm{Cl}_{2}$ and $\mathbf{2} \cdot \mathrm{Ph}_{2}$. A cyclic voltammogram of $\mathbf{2} \cdot \mathrm{Cl}_{2}$ in dichloromethane (1.0 mM analyte, $0.1 \mathrm{M} n \mathrm{Bu}_{4} \mathrm{NPF}_{6}$ supporting electrolyte, $T=293 \mathrm{~K}$, scan rate $=100 \mathrm{mV} / \mathrm{s}$, glassy carbon working electrode) shows an electrochemically irreversible wave in the positive sweep with anodic peak potential $E_{p a}=+0.83 \mathrm{~V}$ vs $\mathrm{Cp}_{2} \mathrm{Fe}^{\mathrm{o} /+}$ (Figure 4, top). By contrast, a cyclic voltammogram of $\mathbf{2} \cdot \mathrm{Ph}_{2}$ under identical experimental conditions shows the presence of a reversible first oxidation event at less positive potentials $E_{1 / 2}=+0.47$ $\mathrm{V}$ vs $\mathrm{Cp}_{2} \mathrm{Fe}^{\mathrm{o} /+}$ (Figure 4 , bottom).
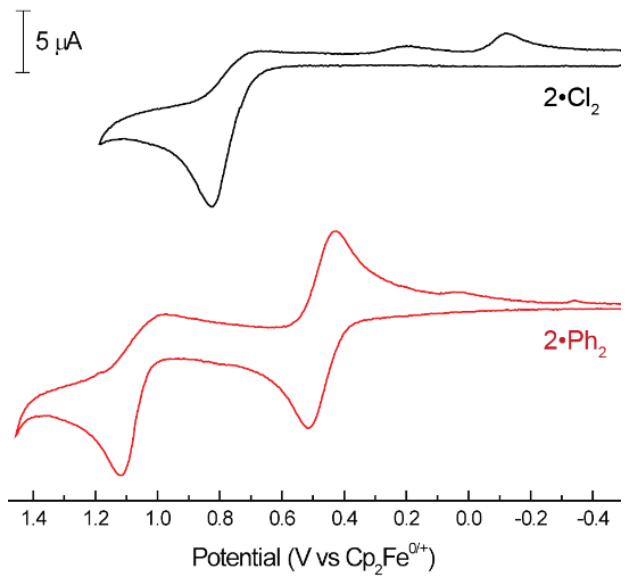

Figure 4. Cyclic voltammograms of $\mathbf{2} \cdot \mathrm{Cl}_{2}$ (black) and $\mathbf{2} \cdot \mathrm{Ph}_{2}$ (red) recorded in $\mathrm{CH}_{2} \mathrm{Cl}_{2}$ solution $\left(1.0 \mathrm{mM}\right.$ analyte, $0.1 \mathrm{M} \mathrm{NBu}_{4} \mathrm{PF}_{6}$ supporting electrolyte, scan rate $100 \mathrm{mV} / \mathrm{s}$, glassy carbon working electrode). 
It is evident that the identity of the basal substituent exerts a controlling effect on the electrochemical behavior of phosphoranes $\mathbf{2} \cdot \mathrm{Cl}_{2}$ and $\mathbf{2} \cdot \mathrm{Ph}_{2}$. Inductive effects presumably are largely responsible for modulating the redox potential of $\mathbf{2} \cdot \mathrm{Cl}_{2}$ and 2. $\mathrm{Ph}_{2}$ over ca. $360 \mathrm{mV}$. Differential strengths and kinetic stabilities of basal $\mathrm{P}-\mathrm{Cl}$ and $\mathrm{P}-\mathrm{C}$ bonds account for the observed (ir)reversibility of the voltammograms. We note that at more positive applied potentials, a second irreversible oxidation event is evident for $2 \cdot \mathrm{Ph}_{2}\left(E_{p a}=+1.12 \mathrm{~V}\right.$ vs $\left.\mathrm{Cp}_{2} \mathrm{Fe}^{\mathrm{o} /+}\right)$; the nature of this oxidation remains the topic of ongoing investigation.

Chemical Oxidation of Phosphorane $2 \cdot \mathrm{Ph}_{2}$. Given the reversibility of the electrochemical response of $\mathbf{2} \cdot \mathrm{Ph}_{2}$, we wished to investigate the possibility of isolating the open-shell product of one electron oxidation. Consistent with the cyclic voltammetry, treatment of $\mathbf{2} \cdot \mathrm{Ph}_{2}$ with the single electron oxidant silver tetrafluoroborate in $\mathrm{CH}_{2} \mathrm{Cl}_{2}\left(\mathrm{E}_{\mathrm{o}}=+0.65 \mathrm{~V}\right.$ vs $\left.\mathrm{Cp}_{2} \mathrm{Fe}^{\mathrm{o} /+}\right)^{37}$ results in a rapid change in color from a clear solution to dark blue and deposition of elemental Ag. These solutions are metastable at room temperature over the course days, but undergo slow decomposition to ill-defined products especially upon concentration. By contrast, stable samples suitable for isolation in single crystalline form may be obtained with noncoordinating barfate anion $\mathrm{BAr}_{4}{ }^{-}=\mathrm{B}\left[\mathrm{C}_{6} \mathrm{H}_{3}-3,5-\left(\mathrm{CF}_{3}\right)_{2}\right]_{4}^{-}$as the counterion.

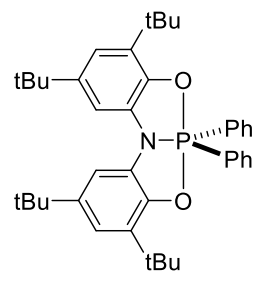

$2 \cdot \mathrm{Ph}_{2}$

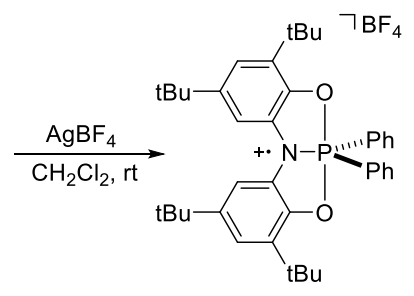

$\left[2 \cdot \mathrm{Ph}_{2}\right] \mathrm{BF}_{4}$
Figure 5. Chemical oxidation of $\mathbf{2} \cdot \mathrm{Ph}_{2}$ with $\mathrm{AgBF}_{4}$.

The solid state structure of the resulting $\left[2 \cdot \mathrm{Ph}_{2}\right] \mathrm{BAr}^{\mathrm{F}}(\mathrm{ob}-$ tained as a pentane solvate) was elucidated through $\mathrm{X}$-ray crystallography and is displayed in Figure 6. To a first approximation, the chemical oxidation $2 \cdot \mathrm{Ph}_{2} \rightarrow\left[2 \cdot \mathrm{Ph}_{2}\right]^{++}$results in only minor global structural changes; Figure 7 depicts a wire-frame overlay of the experimentally determined structures $\mathbf{2} \cdot \mathrm{Ph}_{2}$ (green) and $\left[2 \cdot \mathrm{Ph}_{2}\right]^{\cdot+}$ (red) demonstrating that both compounds present qualitatively similar local structures about the phosphorus center. Upon closer inspection, though, several noteworthy structural aspects are discernable (see Table 1 for selected bond lengths and angles). A slight apparent distortion from an idealized trigonal bipyramid toward a square pyramidal structure $(\tau=0.54)$ is apparent; this distortion is associated with slight folding of the $O N O$ supporting structure as given by $\angle \mathrm{O}_{1}-\mathrm{P}_{1}-\mathrm{O}_{2}=166.7(1)^{\circ}\left(\Delta_{2} \cdot \mathrm{Ph}_{2} 0 / \cdot+=-8.0^{\circ}\right)$, and a rocking of the two phenyl moieties such that $\angle \mathrm{N}_{1}-\mathrm{P}_{1}-\mathrm{C}_{1}=134.2(1)^{\circ}$ $\left(\Delta_{2} \cdot \mathrm{Ph}_{2}{ }^{0 / \cdot+}=+11.8^{\circ}\right)$ and $\angle \mathrm{N}_{1}-\mathrm{P}_{1}-\mathrm{C}_{7}=111.9(1)^{\circ}\left(\Delta_{2} \cdot \mathrm{Ph}_{2} 0 / \cdot+=\right.$ $\left.11.7^{\circ}\right)$. Attending these changes in bond angles, several differences are also observed in bond lengths. While both $\mathrm{P}-\mathrm{C}_{\text {phenyl }}$ bond lengths do not change, $d\left(\mathrm{C}_{1}-\mathrm{P}_{1}\right)=1.810(3) \AA\left(\Delta_{2} \cdot \mathrm{Ph}_{2} 2 / \cdot+=\right.$ $+0.003 \AA)$ and $d\left(\mathrm{C}_{7}-\mathrm{P}_{1}\right)=1.805(4) \AA\left(\Delta_{2} \cdot \mathrm{Ph}_{2} 0 / \cdot+=+0.005 \AA\right)$, the bond distances from phosphorus to nitrogen and one oxygen of the $O N O$ heteroatoms increase. The most significant change occurs to the diarylamido nitrogen, where $d\left(\mathrm{~N}_{1}-\mathrm{P}_{1}\right)=1.786(3)$ $\AA\left(\Delta_{2 \cdot \mathrm{Ph}_{2} 2 / \cdot+}=+0.09 \AA\right)$. Along with this change, there is an apparent increase in the quinoidal character of the $O N O$ fragment; the $\mathrm{N}_{1}-\mathrm{C}_{\text {ipso }}$ bond distances, which had been nearly identical in $\mathbf{2} \cdot \mathrm{Ph}_{2}(1.397(2) \AA$ and $1.394(2) \AA$ ), are noticeably dissymmetric in $\left[2 \cdot \mathrm{Ph}_{2}\right]^{++}(1.391(4) \AA$ and $1.365(3) \AA)$. From these data, it is apparent that single electron oxidation of $\mathbf{2} \bullet \mathrm{Ph}_{2}$ results in subtle yet discernable metrical changes in structure, both locally in the immediate binding environment of phosphorus and also throughout the $O N O$ framework.

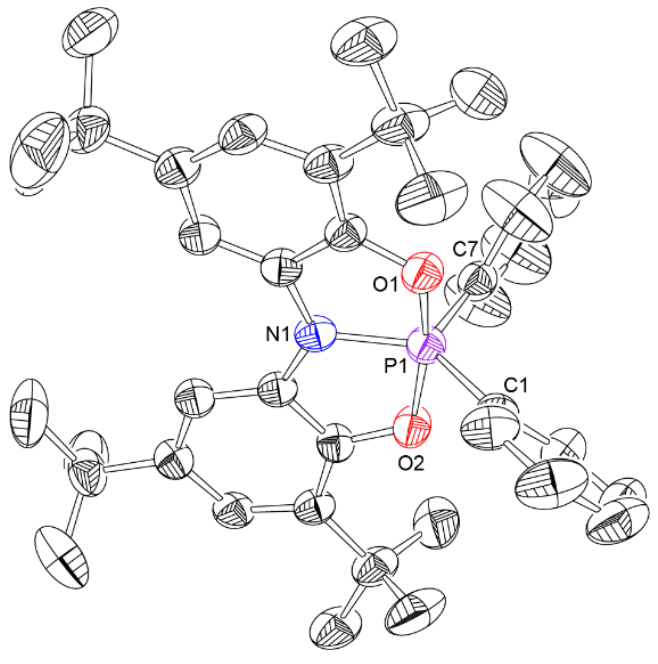

Figure 6. Solid state structure of the open-shell phosphorane 2 $\cdot \mathrm{Ph}_{2}{ }^{*+}$. Thermal ellipsoids shown at $50 \%$ probability with the $\mathrm{B}\left[3,5-\left(\mathrm{CF}_{3}\right)-\mathrm{C}_{6} \mathrm{H}_{3}\right]_{4}{ }^{-}$counter ion, a disordered pentane solvent molecule, and hydrogen atoms omitted for clarity.

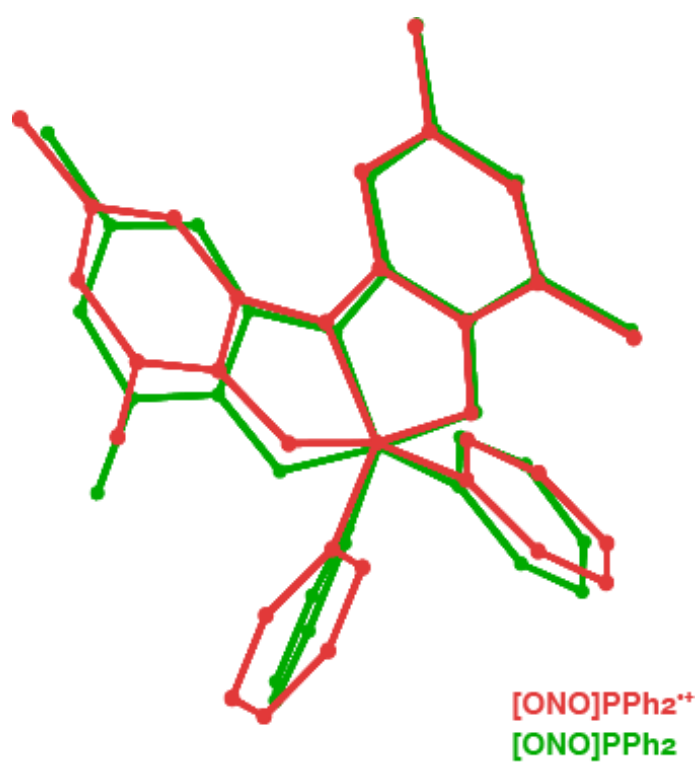

Figure 7. Wire frame overlay of the solid state structures for $\mathbf{2} \cdot \mathrm{Ph}_{2}$ (green) and $\left[\mathbf{2} \cdot \mathrm{Ph}_{2}\right]^{\cdot+}($ red $)$. Methyl groups, hydrogen atoms, and counterions omitted for clarity. 
Table 1. Selected bond lengths $(\AA)$ and angles $\left({ }^{\circ}\right)$ for $2 \cdot \mathbf{P h}_{2}$ and $\left[2 \cdot \mathbf{P P h}_{2}\right]^{++}$.

\begin{tabular}{|l|l|l|}
\hline Metric & $\mathbf{2} \cdot \mathrm{Ph}_{2}$ & {$\left[\mathbf{2} \cdot \mathrm{PPh}_{2}\right]^{++}$} \\
\hline $\mathrm{C}_{1}-\mathrm{P}_{1}$ & $1.807(2)$ & $1.810(3)$ \\
\hline $\mathrm{C}_{7}-\mathrm{P}_{1}$ & $1.800(2)$ & $1.805(4)$ \\
\hline $\mathrm{N}_{1}-\mathrm{P}_{1}$ & $1.699(2)$ & $1.786(3)$ \\
\hline $\mathrm{O}_{1}-\mathrm{P}_{1}$ & $1.6985(18)$ & $1.693(2)$ \\
\hline $\mathrm{O}_{2}-\mathrm{P}_{1}$ & $1.7048(18)$ & $1.736(2)$ \\
\hline $\mathrm{C}_{7}-\mathrm{P}_{1}-\mathrm{C}_{1}$ & $114.04(10)$ & $113.7(1)$ \\
\hline $\mathrm{O}_{1}-\mathrm{P}_{1}-\mathrm{N}_{1}$ & $87.55(7)$ & $86.1(1)$ \\
\hline $\mathrm{O}_{1}-\mathrm{P}_{1}-\mathrm{O}_{2}$ & $174.72(6)$ & $166.7(1)$ \\
\hline $\mathrm{O}_{2}-\mathrm{P}_{1}-\mathrm{N}_{1}$ & $87.46(7)$ & $85.3(1)$ \\
\hline $\mathrm{N}_{1}-\mathrm{P}_{1}-\mathrm{C}_{1}$ & $122.37(8)$ & $134.2(1)$ \\
\hline $\mathrm{N}_{1}-\mathrm{P}_{1}-\mathrm{C}_{7}$ & $123.59(9)$ & $111.9(1)$ \\
\hline
\end{tabular}

Spectroscopic and Computational Investigations of $\left[2 \cdot \mathrm{Ph}_{2}\right] B \mathrm{~F}_{4}$. The absorption profile for each of the three compounds $\mathbf{2} \cdot \mathrm{Cl}_{2}, \mathbf{2} \cdot \mathrm{Ph}_{2}$, and $\left[\mathbf{2} \cdot \mathrm{Ph}_{2}\right] \mathrm{BF}_{4}$ was recorded using UVvis spectroscopy, as shown in Figure 8 . The compound $\mathbf{2} \cdot \mathrm{Cl}_{2}$ displayed a single absorption centered at $\lambda_{\max }=285 \mathrm{~nm}$; the high-energy of this transition is not unexpected for a closedshell phosphorane species. Similarly, the neutral diphenyl phosphorane $\mathbf{2} \cdot \mathrm{Ph}_{2}$ displayed a similar absorption profile with a single absorption band slightly to the red at $\lambda_{\max }=307 \mathrm{~nm}$. By contrast, the absorption profile of the open shell species $\left[\mathbf{2} \cdot \mathrm{Ph}_{2}\right] \mathrm{BF}_{4}$ exhibits several lower energy features; a broad absorption centered at $665 \mathrm{~nm}$ with a shoulder appearing at $617 \mathrm{~nm}$ is apparent in the visible region of the spectrum, with additional absorptions at $354 \mathrm{~nm}$ and $371 \mathrm{~nm}$.

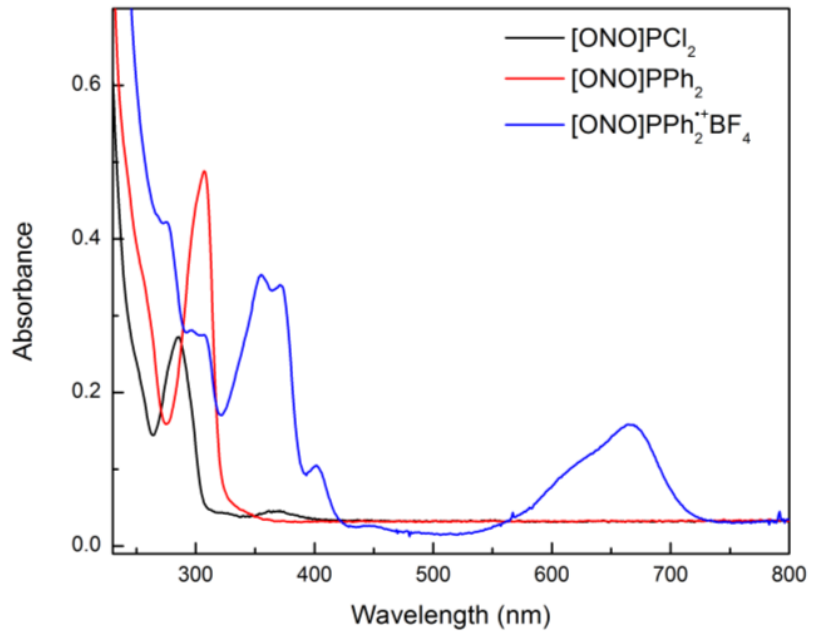

Figure 8. UV-vis absorption spectra recorded for $\mathbf{2} \cdot \mathrm{Cl}_{2}$ (black, 20 $\mu \mathrm{M}$ in $\left.\mathrm{CH}_{2} \mathrm{Cl}_{2}\right), \mathbf{2} \cdot \mathrm{Ph}_{2}\left(\right.$ red, $20 \mu \mathrm{M}$ in $\left.\mathrm{CH}_{2} \mathrm{Cl}_{2}\right)$, and $\left[\mathbf{2} \cdot \mathrm{Ph}_{2}\right] \mathrm{BF}_{4}$ $\left(60 \mu \mathrm{M}\right.$ in $\left.\mathrm{CH}_{2} \mathrm{Cl}_{2}\right)$ at ambient temperature.

The paramagnetic complex $\left[\mathbf{2} \cdot \mathrm{Ph}_{2}\right] \mathrm{BF}_{4}$ was further probed with the use of EPR spectroscopy; the experimental spectrum as well as a simulated spectrum are displayed in Figure 9. The room temperature, solution phase $\left(\mathrm{CH}_{2} \mathrm{Cl}_{2}\right) \mathrm{EPR}$ spectrum of $\left[\mathbf{2} \cdot \mathrm{Ph}_{2}\right] \mathrm{BF}_{4}$ displays spectral envelope centered at $\mathrm{g}=2.006$, with an apparent 9-line coupling pattern. The observed splitting was interpreted by accounting for two pairs of equivalent ${ }^{1} \mathrm{H}$ nuclei with isotropic hyperfine coupling constants of 9.2 $\mathrm{MHz}$ and $2.1 \mathrm{MHz}$; a ${ }^{14} \mathrm{~N}$ hyperfine coupling constant of 13.4 $\mathrm{MHz}$, and a ${ }^{31} \mathrm{P}$ hyperfine coupling constant of $43.5 \mathrm{MHz}$. Both the $g$-value and the extracted hyperfine coupling indicate extensive delocalization of the spin density onto the $O N O$ ligand scaffold. Substantial hyperfine coupling of the two pairs of equivalent ${ }^{1} \mathrm{H}$ nuclei indicates equal distribution of spin density over the two phenyl moieties of the $O N O$ ligand scaffold. The observed ${ }^{31} \mathrm{P}$ hyperfine coupling constant is seemingly large, however we note that it is at least an order of magnitude smaller than typical value for phosphorus-centered radicals $^{38,}$ and thus indicate rather small unpaired spin population on this atom.

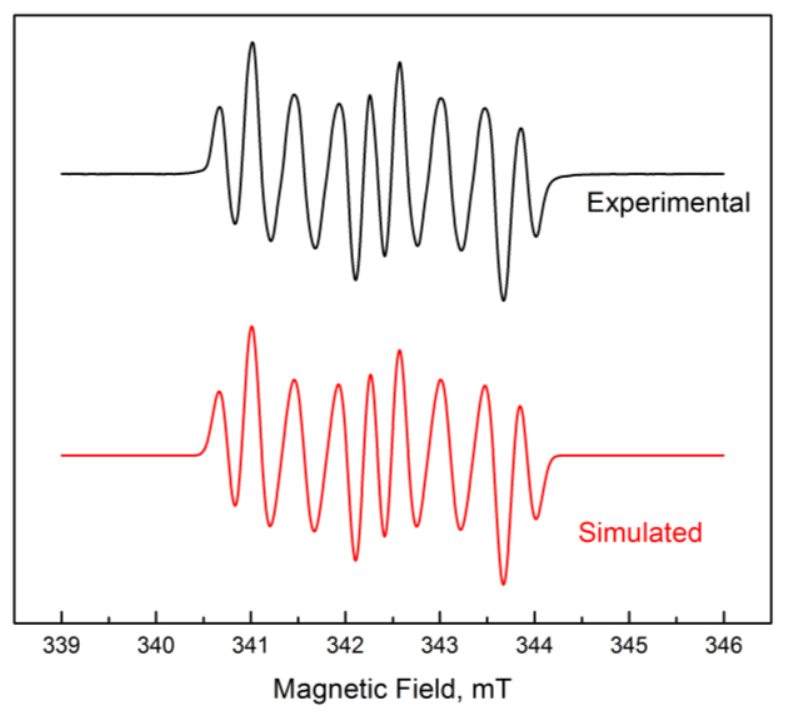

Figure 9. (black) X-band EPR spectra $(9.61 \mathrm{GHz})$ of [X·Ph$]$ B Ar ${ }^{\mathrm{F}}$ in $\mathrm{CH}_{2} \mathrm{Cl}_{2}$ at $293 \mathrm{~K}$. (red) Simulated spectrum with hyperfine fitting parameters as shown in Table 2.

Density functional theory (DFT) calculations were performed to gain further insight into the molecular and electronic structure associated with the ligand centered oxidation event. Geometry optimization and electronic structure calculation for $\left[\mathbf{2} \cdot \mathrm{Ph}_{2}\right]^{\bullet+}$ using DFT (unrestricted BP86 functional and $6-311+g(d)$ basis set on all atoms, followed by single point calculation at the B3LYP/def-TZVPP level of theory) were performed using the crystallographically determined X-ray coordinates as an initial guess geometry. The theoretically predicted structure is in good metrical agreement with the experimental structure. The spin density plot for $\left[\mathbf{2} \cdot \mathrm{Ph}_{2}\right]^{++}$is displayed in Figure 10. The singly occupied molecular orbital (SOMO) shows significant delocalization across the $O N O$ supporting framework, indicating that the single electron oxidation of $\mathbf{2} \cdot \mathrm{Ph}_{2} \rightarrow\left[\mathbf{2} \cdot \mathrm{Ph}_{2}\right]^{\cdot+}$ is almost entirely ligand based. By contrast, the central phosphorus center is found to have little spin density (Mulliken spin population 0.003). Indeed, the hyperfine coupling constants predicted by this spin distribution were found to match closely to those obtained experimentally (Table 2). The spin density distribution obtained resem- 
bles the group 14 compounds of the similar scaffold obtained and characterized by Stegmann and Scheffler. ${ }^{11-13}$ In all cases, the spin density was found to be largely distributed over the ONO structure. The notable difference is more localized spin density on the peripheral carbons in the current case: ratio $\mathrm{A}\left(\mathrm{H}-\mathrm{C}_{15,31}\right) / \mathrm{A}\left(\mathrm{H}-\mathrm{C}_{17,29}\right)$ is about 4.4 for $\left[\mathbf{2} \cdot \mathrm{Ph}_{2}\right]^{+}$as compared to about 2 for $(O N O) \mathrm{PbAr}_{2},(O N O) \mathrm{SnAr}_{2}$, and $(O N O) \mathrm{GeAr}_{2}$ compounds. This difference in the spin distribution is also apparent from about $30 \%$ smaller $\mathrm{A}\left({ }^{14} \mathrm{~N}\right)$ of the central nitrogen (cf. Table S7, Supporting Information).

Table 2. Comparison of experimental (EPR) and calculated (DFT) isotropic hyperfine coupling constants.

\begin{tabular}{|l|l|l|l|}
\hline Nucleus $^{\mathrm{a}}$ & Assignment $^{\mathrm{b}}$ & Experimental $^{\mathrm{c}}$ & Calculated $^{\mathrm{c}}$ \\
\hline${ }^{1} \mathrm{H}(2)$ & $\mathrm{C}_{15}-\mathrm{H} / \mathrm{C}_{31}-\mathrm{H}$ & 9.2 & 8.7 \\
\hline${ }^{1} \mathrm{H}(2)$ & $\mathrm{C}_{17}-\mathrm{H} / \mathrm{C}_{29}-\mathrm{H}$ & 2.1 & 1.24 \\
\hline${ }^{14} \mathrm{~N}$ & $\mathrm{~N}_{1}$ & 13.4 & 10.1 \\
\hline${ }^{31} \mathrm{P}$ & $\mathrm{P}_{1}$ & 43.5 & 44.3 \\
\hline
\end{tabular}

${ }^{a}$ Nucleus responsible for observed hyperfine coupling. Parentheses indicated number of equivalent nuclei. ${ }^{b}$ Atom labels refer to structure depicted in Figure S2. ${ }^{c}$ Values in MHz.

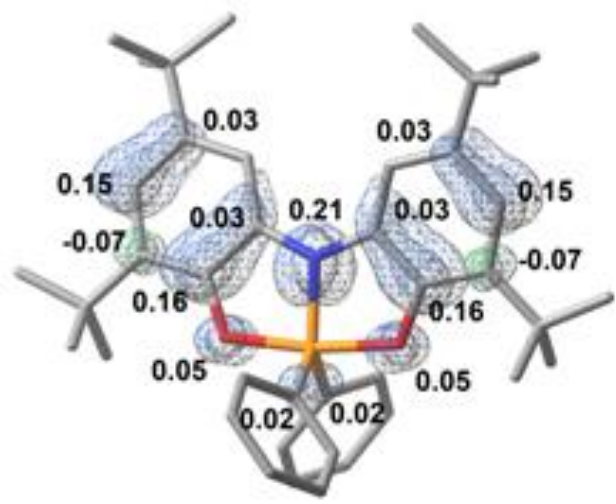

Figure 10. Geometry optimized structure of $\left[\mathbf{2} \cdot \mathrm{Ph}_{2}\right]^{\cdot+}(\mathrm{B} 3 \mathrm{LYP} /$ def-TZVPP//B86/6-311+g(d)) superimposed with spin density plot (blue - positive density, green - negative density). Relevent Mulliken spin populations are noted.

In view of the small structural changes associated with the oxidation of $\mathbf{2} \cdot \mathrm{Ph}_{2} \rightarrow\left[\mathbf{2} \cdot \mathrm{Ph}_{2}\right]^{\cdot+}$ and the reversibility of this process, we undertook investigations of the rate of electron transfer self-exchange using the method of ${ }^{1} \mathrm{H}$ NMR linebroadening. ${ }^{39}$ For a pure sample of closed-shell phosphorane $\mathbf{2} \cdot \mathrm{Ph}_{2}$, a resonance at $\delta 1.31 \mathrm{ppm}$ is observed for one of the tert-butyl groups on the ligand periphery. The line width (determined as the full-width at half-maximum height by spectral fitting of the Lorentzian line shape) is estimated at 4.3(5) Hz. By contrast, the ${ }^{1} \mathrm{H}$ NMR spectrum of $\left[2 \cdot \mathrm{Ph}_{2}\right]^{\cdot+}$ shows a very broad resonance at $\delta 1.74 \mathrm{ppm}$ with an estimated line width of 153(10) Hz. A series of ${ }^{1} \mathrm{H}$ NMR spectra were recorded at room temperature with varying mole fraction of the neutral compound $\mathbf{2} \cdot \mathrm{Ph}_{2}$ and the oxidized species $\left[\mathbf{2} \cdot \mathrm{Ph}_{2}\right]^{\cdot+}$ (Table 3 ). Starting from pure $\mathbf{2} \cdot \mathrm{Ph}_{2}$, increases in the quantity of paramagnetic species $\left[\mathbf{2} \cdot \mathrm{Ph}_{2}\right]^{\bullet+}$ causes the tert-butyl resonance to shift downfield and broaden. A linear relationship between mole fraction of $\left[\mathbf{2} \cdot \mathrm{Ph}_{2}\right]^{\bullet+}$ and chemical shift is observed. The rate constant $\left(k_{e x}\right)$ for the electron transfer self-exchange be- tween compound $\mathbf{2} \cdot \mathrm{Ph}_{2}$ and $\left[\mathbf{2} \cdot \mathrm{Ph}_{2}\right]^{++}$was determined according to eq 1 , where $\chi_{d}$ and $\chi_{p}$ represent the mole fraction of $2 \cdot \mathrm{Ph}_{2}$ and $\left[2 \cdot \mathrm{Ph}_{2}\right]^{\bullet+}$, respectively; $\Delta v$ is the difference in frequencies $(\mathrm{Hz})$ between diamagnetic $\mathbf{2} \cdot \mathrm{Ph}_{2}$ and paramagnetic $\left[2 \cdot \mathrm{Ph}_{2}\right]^{\bullet+} ; C_{t o t}$ is the total concentration; $w_{p}$ and $w_{d}$ are the line width at half-maximum for pure samples $\mathbf{2} \cdot \mathrm{Ph}_{2}$ and $\left[\mathbf{2} \cdot \mathrm{Ph}_{2}\right]^{\bullet+}$, respectively; and $w_{p d}$ is the line width at half-maximum for the mixture.

Table 3. Data for electron self-exchange NMR linebroadening experiments.

\begin{tabular}{|l|l|l|l|l|}
\hline$\chi_{\mathrm{d}}$ & $\chi_{\mathrm{p}}$ & Shift $(\mathrm{Hz})$ & $\begin{array}{l}\text { Line } \\
\text { Width } \\
(\mathrm{Hz})\end{array}$ & $\begin{array}{l}k_{\mathrm{ex}} \\
\left(\mathrm{x} \mathrm{10} 0^{5}\right.\end{array}$ \\
\hline 1 & 0 & 657.59 & 4.32 & \\
\hline 0.945 & 0.055 & 669.28 & 22.52 & 1.2 \\
\hline 0.886 & 0.114 & 681.93 & 35.94 & 1.6 \\
\hline 0.843 & 0.157 & 691.1 & 48.36 & 1.5 \\
\hline 0.735 & 0.265 & 714.05 & 67.68 & 1.9 \\
\hline 0.403 & 0.597 & 785.03 & 112.48 & 2.9 \\
\hline 0 & 1 & 870.97 & 153.43 & \\
\hline
\end{tabular}

$$
k_{e x}=\frac{4 \pi \chi_{p} \chi_{d}(\Delta v)^{2}}{C_{t o t}\left(w_{p d}-\chi_{p} w_{p}-\chi_{d} w_{d}\right)}
$$

Averaging the obtained rate constants $k_{e x}$ over the experimental concentration range in Table 3 , we estimate the selfexchange rate between compounds $\mathbf{2} \cdot \mathrm{Ph}_{2}$ and $\left[\mathbf{2} \cdot \mathrm{Ph}_{2}\right]^{\cdot+}$ at $k_{e x}=$ $1.8(7) \times 10^{5} \mathrm{M}^{-1} \cdot \mathrm{s}^{-1}$. Although it is of note that small changes in the estimated width at half-maximum height can have a dramatic effect upon the precise obtained rate constant, the comparison of the solid state structures of the two compounds nonetheless supports the notion of a rapid electron transfer self-exchange due to only minor structural reorganization.

\section{CONCLUSIONS}

The synthesis and study of phosphorus(V) bound within a redox active $O N O$ ligand scaffold has been presented. The phosphorus compounds $\mathbf{2} \cdot \mathrm{Cl}_{2}$ and $\mathbf{2} \cdot \mathrm{Ph}_{2}$ can be synthesized in high yields and have been structurally characterized. The electrochemistry of these systems was probed with the use of cyclic voltammetry, with the compound $\mathbf{2} \cdot \mathrm{Cl}_{2}$ showing only a single irreversible oxidation, while the diphenyl phosphorene $\mathbf{2} \cdot \mathrm{Ph}_{2}$ displays a reversible one-electron oxidation event. Compound $\mathbf{2} \cdot \mathrm{Ph}_{2}$ was chemically oxidized with silver salts to form the radical cation, $\left[\mathbf{2} \cdot \mathrm{Ph}_{2}\right]^{\bullet+}$. EPR spectroscopy and DFT calculations revealed that the unpaired spin density in $\left[2 \cdot \mathrm{Ph}_{2}\right]^{++}$ is largely ligand based and is highly delocalized throughout the $O N O$ supporting framework of the paramagnetic species. The solid state structures and self-exchange NMR linebroadening experiments indicate that the electron transfer is swift with only modest metrical changes between the neutral and oxidized species. 


\section{EXPERIMENTAL SECTION}

Methylene chloride $\left(\mathrm{CH}_{2} \mathrm{Cl}_{2}\right)$, pentane and toluene were dried according to the method of Grubbs ${ }^{40}$ as modified by Bergman ${ }^{41}$. All commercially available reagents were purchased from suppliers and used without further purification. All reactions were carried out under nitrogen either in a double port glovebox (Innovative Technology) or with a Schlenk manifold vented through an oil bubbler unless otherwise noted. All glassware was oven-dried at $120{ }^{\circ} \mathrm{C}$ prior to use. $\mathrm{Zn}$ complex $\mathbf{1},{ }^{33}$ and $\mathrm{AgBAr}{ }^{\mathrm{F} 42}$ were synthesized according to previous reports. Mass spectrometric data were obtained from the University of Illinois Mass Spectrometry Lab. Elemental analysis data was obtained from Midwest Microlab, Indianapolis, IN.

Spectroscopic Methods. ${ }^{1} \mathrm{H},{ }^{13} \mathrm{C}$, and ${ }^{31} \mathrm{P}$ NMR spectra were recorded with a Bruker AV-360, DRX-400 or AV-3-500 spectrometers. $\mathrm{CDCl}_{3}$ and $\mathrm{CD}_{2} \mathrm{Cl}_{2}$ were purchased from Cambridge Isotopes Laboratories and stored over activated $4 \AA$ molecular sieves in the glovebox prior to use. ${ }^{1} \mathrm{H}$ and ${ }^{13} \mathrm{C}$ NMR spectra were referenced to residual proto-solvent resonances (chloroform $7.26 \mathrm{ppm} ; 77.16 \mathrm{ppm}$ ). ${ }^{31} \mathrm{P}$ NMR spectra were referenced to an external standard $\left(\mathrm{H}_{3} \mathrm{PO}_{4} 0.0\right.$ ppm). EPR spectra were recorded using a Bruker ESP300 equiped with ER041MR MW bridge and a ER 4116DM dual mode resonator. The EPR spectrum was recorded using the following settings: MW power $=0.02 \mathrm{~mW}$, MW frequency $=9.6122 \mathrm{GHz}$, sweep width $=80.0$ $\mathrm{G}$, modulation amplitude $=0.2 \mathrm{G}$, conversion time $=40.96 \mathrm{~ms}$, and time constant $=40.96 \mathrm{~ms}$. EPR simulation was performed utilizing the "garlic" routine from EasySpin for MatLab ${ }^{43}$ and aided by a homewritten automatic spectral fitting routine. The UV-vis spectroscopy was performed using a Cary 500 spectrometer with analyte solutions prepared using dichloromethane as the solvent. The UV-vis spectrum of $\left[2 \cdot \mathrm{Ph}_{2}\right] \mathrm{BF}_{4}$ was acquired using dichloromethane that was freshly distilled from $\mathrm{CaH}_{2}$ and a quartz cuvette that had been silylated using TMS-Cl ( $5 \%$ by volume solution in dichloromethane), rinsed ( $3 \mathrm{x}$ dichloromethane) and dried thoroughly in an oven.

Electrochemistry. All electrochemistry experiments were performed using a Pine WaveNow XV potentiostat. Cyclic voltammetry was performed at ambient temperature in a nitrogen filled glove box using a standard three-electrode configuration. CV scans were recorded using a glassy carbon working electrode $(3.0 \mathrm{~mm}$ diameter $)$, platinum mesh as the counter electrode and a silver wire separated by a porous Teflon tip and submerged in $\mathrm{TBAPF}_{6}$ solution $(0.1 \mathrm{M})$ as a quasi-reference electrode. The phosphorus analytes $(1.0 \mathrm{mM})$ were prepared in dichloromethane with tetrabutylammonium hexafluorophosphate $(0.1 \mathrm{M})$ as the supporting electrolyte. Sublimed ferrocene $(1.0 \mathrm{mM})$ was added at the end of each experiment as the internal reference.

Electron Self Exchange. ${ }^{1} \mathrm{H}$ NMR spectra were acquired in $\mathrm{CD}_{2} \mathrm{Cl}_{2}$ on a Bruker AV-3-500 spectrometer at $298 \mathrm{~K}$. The samples were prepared in a nitrogen filled glovebox and from stock solutions of each analyte $\left(25 \mathrm{mM}\right.$ in $\left.\mathrm{CD}_{2} \mathrm{Cl}_{2}\right)$ in varying ratios for a total volume of $0.5 \mathrm{~mL}$. The mole fractions, chemical shifts and experimental values for the peaks widths $(W)$ are displayed in Table 2 . The peak widths were determined by Lorentzian line-fitting using the MestReNova 10 software.

X-ray Diffraction Methods. Single crystals of $\mathbf{2} \cdot \mathrm{Ph}_{2}$ and [2・Ph 2$]\left(\mathrm{B}\left[\mathrm{C}_{6} \mathrm{H}_{3}-3,5-\left(\mathrm{CF}_{3}\right)_{2}\right]_{4}\right)$ were selected and mounted on a loop using paratone oil on a Bruker SMART APEX diffractometer. The crystal was kept at $213 \mathrm{~K}$ during data collection. Using Olex2 $2^{44}$, the structure was solved with the ShelXS ${ }^{45}$ structure solution program using Direct Methods and refined with the XL refinement package using Least Squares minimization.

Computational Methods. Density functional theory (DFT) calculations were performed using Gaussian 09 package $^{46}$. Geometry of the oxidized compound was obtained by gas-phase geometry optimization using unrestricted BP86 functional and 6-311+G(d) basis set on all atoms. Starting coordinates were extracted from the crystal structure of $\mathbf{2} \cdot \mathrm{Ph}_{2}$. To aid geometry optimization, rotation of all methyl groups was restricted by freezing one of the associated HC-CC dihedral angles. Subsequently, single point gas-phase calculations were per- formed utilizing unrestricted B3LYP functional and def-TZVPP basis set on all atoms.

Synthesis of $\mathbf{2} \cdot \mathbf{C l}_{\mathbf{2}}$. The title compound was synthesized with slight modification of literature procedure ${ }^{32}$ To a solution of the zinc complex $1(2.5 \mathrm{~g}, 2.74 \mathrm{mmol})$ in $50 \mathrm{~mL}$ of dry toluene in a Schlenk flask, $\mathrm{PCl}_{3}(2.4 \mathrm{~mL}, 27.4 \mathrm{mmol})$ was added dropwise at room temperature with vigorous stirring. After stirring for $2 \mathrm{~h}$ at room temperature under nitrogen, the solvent was removed in vacuo leaving a purple solid. The solid was triturated with pentane, filtered and the solvent was removed. The light purple solid was dissolved in a minimal amount of pentane and put into the freezer at $-35{ }^{\circ} \mathrm{C}$. The product precipitated from solution as a white solid $(2.1 \mathrm{~g}, 73 \%) .{ }^{1} \mathrm{H}$ NMR $\left(\mathrm{CDCl}_{3}, 360\right.$

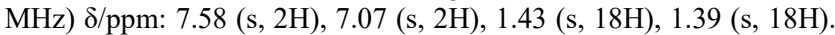
${ }^{31} \mathrm{P}$ NMR $\left(\mathrm{CDCl}_{3}, 145 \mathrm{MHz}\right) \delta / \mathrm{ppm}:-20.1$.

Synthesis of $\mathbf{2} \cdot \mathbf{P h} \mathbf{h}_{2}$. To a solution of the zinc complex $\mathbf{1}(1 \mathrm{~g}, 1.1$ mmol $)$ in $50 \mathrm{~mL}$ of dry toluene in a Schlenk flask, $\mathrm{Ph}_{2} \mathrm{PCl}(406 \mu \mathrm{L}$, $2.2 \mathrm{mmol}$ ) was added dropwise at room temperature with vigorous stirring. After stirring for $4 \mathrm{~h}$ at room temperature under nitrogen, the solvent was removed in vacuo leaving a purple solid. The solid was triturated with cold pentane, filtered and the solvent was removed. The light purple solid was dissolved in a minimal amount of pentane and put into the freezer at $-35{ }^{\circ} \mathrm{C}$. The product precipitated from solution as a white solid $(1.05 \mathrm{~g}, 79 \%)$. Single crystals of the product were grown by slow evaporation of an acetonitrile/dichloromethane solution. ${ }^{1} \mathrm{H}$ NMR $\left(\mathrm{CD}_{2} \mathrm{Cl}_{2}, 500 \mathrm{MHz}\right) \delta / \mathrm{ppm}: 7.80(\mathrm{~d}, J=7.0 \mathrm{~Hz}, 2 \mathrm{H})$, $7.77(\mathrm{~d}, J=7.2 \mathrm{~Hz}, 2 \mathrm{H}), 7.62(\mathrm{~s}, 2 \mathrm{H}), 7.45-7.40(\mathrm{~m}, 2 \mathrm{H}), 7.40-7.34$ $(\mathrm{m}, 4 \mathrm{H}), 6.94(\mathrm{~s}, 2 \mathrm{H}), 1.38(\mathrm{~s}, 18 \mathrm{H}), 1.31(\mathrm{~s}, 18 \mathrm{H}) .{ }^{13} \mathrm{C} \mathrm{NMR}\left(\mathrm{CD}_{2} \mathrm{Cl}_{2}\right.$, $126 \mathrm{MHz}) \delta / \mathrm{ppm}: 143.93(\mathrm{~d}, J=4.4 \mathrm{~Hz}), 142.32,140.84,139.42$, $132.04(\mathrm{~d}, J=12.1 \mathrm{~Hz}), 131.15(\mathrm{~d}, J=3.6 \mathrm{~Hz}), 129.02(\mathrm{~d}, J=19.6$ $\mathrm{Hz}), 128.23(\mathrm{~d}, J=16.3 \mathrm{~Hz}), 116.35,107.13(\mathrm{~d}, J=13.0 \mathrm{~Hz}), 35.31$, 34.71, 32.13, 30.05. ${ }^{31} \mathrm{P} \mathrm{NMR}\left(\mathrm{CDCl}_{3}, 145 \mathrm{MHz}\right) \delta / \mathrm{ppm}:-27.9$. HRMS $\left(\mathrm{EI}^{+}\right) \mathrm{m} / \mathrm{z}$ calcd for $\mathrm{C}_{40} \mathrm{H}_{50} \mathrm{NO}_{2} \mathrm{P}$ : 607.3579; found: 607.3573 . Anal. Calcd (Found) for $\mathrm{C}_{40} \mathrm{H}_{50} \mathrm{NO}_{2} \mathrm{P}$ : C 79.0 (78.9); $\mathrm{H} 8.3$ (8.1); N 2.30 (2.5); P 5.1 (5.4).

Synthesis of $\left[\mathbf{2} \cdot \mathbf{P h}_{2}\right] \mathbf{B F}_{\mathbf{4}}$ (4). Compound $\mathbf{2} \cdot \mathrm{Ph}_{2}$ (400 mg, 0.66 mmol) was dissolved in $8 \mathrm{~mL}$ of dry $\mathrm{CH}_{2} \mathrm{Cl}_{2}$ and was added to a solution of $\mathrm{AgBF}_{4}(128 \mathrm{mg}, 0.66 \mathrm{mmol})$ dissolved in $8 \mathrm{~mL}$ of $\mathrm{CH}_{2} \mathrm{Cl}_{2}$. The reaction stirred at room temperature for $4 \mathrm{~h}$ and was filtered and the solvent was removed under reduced pressure. The resulting dark blue solid was washed with pentane and dried to give the title compound $(420 \mathrm{mg}, 92 \%)$. HRMS $\left(\mathrm{EI}^{+}\right) \mathrm{m} / \mathrm{z}$ calcd for $\mathrm{C}_{40} \mathrm{H}_{50} \mathrm{NO}_{2} \mathrm{P}$ : 607.3579; found: 607.3577. Anal. Calcd (Found) for $\mathrm{C}_{40} \mathrm{H}_{50} \mathrm{BF}_{4} \mathrm{NO}_{2} \mathrm{P}$ : C 69.2 (68.8); H 7.3 (7.3); N 2.0 (2.0).

Synthesis of $\left[\mathbf{2} \cdot \mathbf{P h} \mathbf{h}_{2}\right] \mathbf{B}\left(\mathbf{3 , 5}-\left(\mathbf{C F}_{3}\right)_{2}-\mathbf{C}_{6} \mathbf{H}_{3}\right)_{4}$. Compound $\mathbf{2} \cdot \mathrm{Ph}_{2}(200$ $\mathrm{mg}, 0.33 \mathrm{mmol}$ ) was dissolved in $4 \mathrm{~mL}$ of dry $\mathrm{CH}_{2} \mathrm{Cl}_{2}$ and was added to a solution of $\mathrm{AgB}\left[3,5-\left(\mathrm{CF}_{3}\right)_{2}-\mathrm{C}_{6} \mathrm{H}_{3}\right]_{4}(320 \mathrm{mg}, 0.33 \mathrm{mmol})$ dissolved in $4 \mathrm{~mL}$ of $\mathrm{CH}_{2} \mathrm{Cl}_{2}$. The reaction stirred at room temperature for $4 \mathrm{~h}$ and was filtered and the solvent was removed under reduced pressure. The resulting dark blue solid was washed with pentane and dried to give the title compound (400 mg, 82\%). Single crystals suitable for x-ray diffraction were prepared by slow evaporation of a 1:3 mixture of diethylether and pentane.

\section{ASSOCIATED CONTENT}

\section{Supporting Information}

${ }^{1} \mathrm{H},{ }^{13} \mathrm{C}$, and ${ }^{31} \mathrm{P}$ NMR spectra for all synthetic compounds; EPR spectra including spectral simulations; crystallographic and computational details. The Supporting Information is available free of charge on the ACS Publications website.

\section{AUTHOR INFORMATION}

\section{Corresponding Author}

*radosevich@mit.edu 


\section{ACKNOWLEDGMENT}

We thank the NSF (CHE- 1724505) for financial support. A.T.R gratefully acknowledges additional support from the Alfred P. Sloan Foundation and Amgen. We thank Dr. Peter Mueller (MIT) for assistance with refinement of diffraction data.

\section{REFERENCES}

1 Kaim, W.; Paretzki, A. Coord. Chem. Rev. 2017, doi: 10.1016/j.ccr.2016.12.008.

${ }^{2}$ Broere, D. L. J.; Plessius, R.; Vlugt, J. I. van der Chem. Soc. Rev. 2015, 44, 6886-6915.

${ }^{3}$ Blackmore, K. J.; Ziller, J. W.; Heyduk, A. F. Inorg. Chem., $\mathbf{2 0 0 5}, 44,5559$

${ }^{4}$ Haneline, M. R.; Heyduk, A. F. J. Am. Chem. Soc., 2006, 128, 8410.

${ }^{5}$ Zarkesh, R. A.; Ziller, J. W.; Heyduk, A. F. Angew. Chem. Int. Ed., 2008, 47, 4715 .

${ }^{6}$ Lyaskovskyy, V.; de Bruin, B. ACS Catalysis, 2012, 2, 270.

${ }^{7}$ Praneeth, V. K. K.; Ringenberg, M. R.; Ward, T. R. Angew. Chem. Int. Ed., 2012, 51, 10228.

${ }^{8}$ Luca, O. R.; Crabtree, R. H. Chem. Soc. Rev., 2013, 42, 1440.

${ }^{9}$ Chirik, P. J. Acc. Chem. Res. 2015, 48, 1687-1695.

${ }^{10}$ Blanchard, S.; Derat, E.; Desage-El Murr, M.; Fensterbank, L.; Malacria, M.; Mouriès-Mansuy, V. Eur. J. Inorg. Chem. 2012, 2012, 376-389.

${ }^{11}$ Stegmann, H. B.; Scheffler, K.; Stocker, F. Angew. Chem. Int. Ed. 1970, 9, 456

${ }^{12}$ Stegmann, H. B.; Scheffler, K. Chem. Ber. 1970, 103, 12791285.

${ }^{13}$ Stegmann, H. B.; Scheffler, K.; Stocker, F. Angew. Chem. Int. Ed. 1970, 10, 499-500.

${ }^{14}$ Zarkesh, R. A.; Heyduk, A. F. Organometallics, 2009, 28, 6629.

${ }^{15}$ Heyduk, A. F.; Zarkesh, R. A.; Nguyen, A. I. Inorg. Chem., 2011, 50, 9849 .

${ }^{16}$ Zarkesh, R. A.; Heyduk, A. F. Organometallics, 2011, 30, 4890.

${ }^{17}$ Hananouchi, S.; Krull, B. T.; Ziller, J. W.; Furche, F.; Heyduk, A. F. Dalton Trans., 2014, 43, 17991.

18 Piskunov, A. V.; Sukhoshkina, O. Yu.; Smolyaninov, I. V. Zhurnal Obshchei Khimii, 2010, 80, 629.

${ }^{19}$ Shekar, S.; Brown, S. N. Organometallics, 2013, 32, 556.

${ }^{20}$ Turek, J.; Kampová, H.; Padělková, Z.; Růžička, A. J. Organomet. Chem., 2013, 745, 25.

${ }^{21}$ Shekar, S.; Brown, S. N. J. Org. Chem., 2014, 79, 12047.

${ }^{22}$ McGarvey, B. R.; Ozarowski, A.; Tian, Z.; Tuck, D. G. Can. J. Chem., 1995, 73, 1213.

${ }^{23}$ Camacho-Camacho, C.; Tlahuext, H.; Nöth, H.; Contreras, R. Heteroatom Chem., 1998, 9, 321.

${ }^{24}$ Camacho-Camacho, C.; Majangos, E.; Castillo-Ramos, M. E.; Esparza-Ruiz, A.; Vásquez-Badillo, A.; Nöth, H.; Flores-Parra, A.; Contreras, R. J. Organomet. Chem., 2010, 695, 833.

${ }^{25}$ Ohkata, K.; Yano, T.; Kuwaki, K.; Akiba, K. Chemistry Letters, 1990, 1721

${ }^{26}$ Poddel'sky, A. I.; Somov, N. V.; Kurskii, Y. A.; Cherkasov, V. K.; Abakumov, G. A. J. Organomet. Chem., 2008, 693, 3451.

${ }^{27}$ Poddel'sky, A. I.; Vavilina, N. N.; Somov, N. V.; Cherkasov, V. K.; Abakumov, G. A. J. Organomet. Chem., 2009, 694, 3462.

${ }^{28}$ Smolyaninov, I. V.; Poddel'skii, A. I.; Berberova, N. T. Elektrokhimiya, 2011, 47, 1295

${ }^{29}$ Smolyaninov, I. V.; Poddel'sky, A. I.; Smolyaninova, S. I.; Berberova, N. T. Koordinatsionnaya Khimiya, 2014, 40, 608.

${ }^{30}$ Chaudhuri, P.; Hess, M.; Weyhermüller, T.; Wieghardt, K. Angew. Chem. Int. Ed. 1999, 38, 1095-1098.
${ }^{31}$ McCarthy, S. M.; Lin, Y.-C.; Devarajan, D.; Chang, J. W.; Yennawar, H. P.; Rioux, R. M.; Ess, D. H.; Radosevich, A. T. J. Am. Chem. Soc. 2014, 136, 4640-4650.

${ }^{32}$ Zhao, W.; McCarthy, S. M.; Lai, T. Y.; Yennawar, H. P.; Radosevich, A. T. J. Am. Chem. Soc. 2014, 136, 17634-17644.

${ }^{33}$ Robinson, T. P.; De Rosa, D. M.; Aldridge, S.; Goicoechea, J. M. Angew. Chem., Int. Ed. 2015, 54, 13758-13763.

${ }^{34}$ Robinson, T. P.; Lo, S.-K.; De Rosa, D.; Aldridge, S.; Goicoechea, J. M. Chem. - Eur. J. 2016, 22, 15712-15724.

${ }^{35}$ Camacho-Camacho, C.; Martinez-Martinez, F. J.; Rosales-Hoz, M. J.; Contreas, R. Phosphorus, Sulfur Silicon Relat. Elem. 1994, 91, 189.

${ }^{36}$ Girgis, A. Y.; Balch, A. L. Inorg. Chem. 1975, 14, 2724.

${ }^{37}$ Connelly, N. G.; Geiger, W. E. Chem. Rev. 1996, 96, 877.

${ }^{38}$ M. Geoffroy, Applications of EPR in Radiation Research, ed. A. Lund and M. Shiotani, Springer International Printing, New York, 2014, Chapter 2, 33-67.

${ }^{39}$ Jameson, D. L.; Anand, R. J. Chem. Ed., 2000, 77, 88.

${ }^{40}$ Pangborn, A. B.; Giardello, M. A.; Grubbs, R. H.; Rosen, R. K.; Timmers, F. J. Organometallics, 1996, 15, 1518.

${ }^{41}$ Alaimo, P. J.; Peters, D. W.; Bergman, R. G. J. J. Chem. Ed., 2001, 78, 64 .

${ }^{42}$ Hayashi, Y.; Rohde, J. J.; Corey, E. J. J. Am. Chem. Soc. 1996, $118,5502$.

${ }^{43}$ Stroll, S.; Schweiger, A. J. Magn. Reson. 2006, 178, 42.

${ }^{44}$ Dolomanov, O. V.; Bourhis, L. J.; Gildea, R. J.; Howard, J. A. K.; Puschmann, H. J. Appl. Cryst. 2009, 42, 339.

${ }^{45}$ Sheldrick, G. M Acta Cryst. 2008, A64, 112.

${ }^{46}$ Frisch, M. J.; Trucks, G. W.; Schlegel, H. B.; Scuseria, G. E.; Robb, M. A.; Cheeseman, J. R.; Scalmani, G.; Barone, V.; Mennucci, B.; Petersson, G. A.; Nakatsuji, H.; Caricato, M.; Li, X.; Hratchian, H. P.; Izmaylov, A. F.; Bloino, J.; Zheng, G.; Sonnenberg, J. L.; Hada, M.; Ehara, M.; Toyota, K.; Fukuda, R.; Hasegawa, J.; Ishida, M.; Nakajima, T.; Honda, Y.; Kitao, O.; Nakai, H.; Vreven, T.; Montgomery, Jr., J. A.; Peralta, J. E.; Ogliaro, F.; Bearpark, M.; Heyd, J. J.; Brothers, E.; Kudin, K. N.; Staroverov, V. N.; Keith, T.; Kobayashi, R.; Normand, J.; Raghavachari, K.; Rendell, A.; Burant, J. C.; Iyengar, S. S.; Tomasi, J.; Cossi, M.; Rega, N.; Millam, J. M.; Klene, M.; Knox, J. E.; Cross, J. B.; Bakken, V.; Adamo, C.; Jaramillo, J.; Gomperts, R.; Stratmann, R. E.; Yazyev, O.; Austin, A. J.; Cammi, R.; Pomelli, C.; Ochterski, J. W.; Martin, R. L.; Morokuma, K.; Zakrzewski, V. G.; Voth, G. A.; Salvador, P.; Dannenberg, J. J.; Dapprich, S.; Daniels, A. D.; Farkas, O.; Foresman, J. B.; Ortiz, J. V.; Cioslowski, J.; Fox, D. J. Gaussian 09, Revision C.01, Gaussian, Inc., Wallingford CT, 2010. 


\section{For Table of Contents Only}

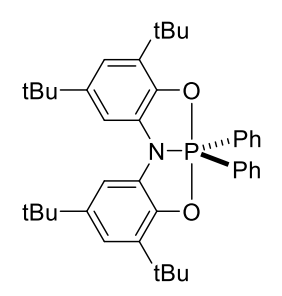

$2 \cdot \mathrm{Ph}_{2}$

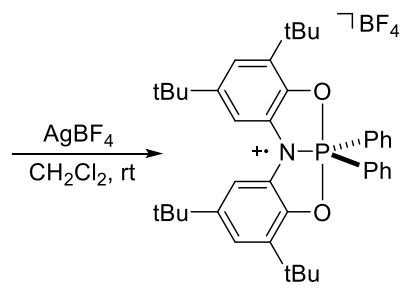

$\left[2 \cdot \mathrm{Ph}_{2}\right] \mathrm{BF}_{4}$

Synopsis: A stable open-shell phosphorane based on a redox active amidodiphenoxide scaffold may be accessed by (electro)chemical oxidation of the closed-shell congener. Spectroscopic investigations indicate that the oxidation is largely localized on the amidodiphenoxide supporting framework. 
